\title{
Treatment of hallux valgus in children and adolescents by chevron's operating technique
}

Fernando Cal Garcia Filho ${ }^{1 *}$, Lucas Cortizo Garcia ${ }^{2}$, Fabio Silveira Matos ${ }^{1}$, Lucas Rocha de Jesus ${ }^{2}$, Magda Leão Pinheiro ${ }^{3}$, Fernanda Cortizo Garcia $^{4}$ and Matheus Vasconcelos Goes Mendes ${ }^{3}$

${ }^{1}$ Residency preceptor in the orthopedic department of the Martagão Gesteira Children's Hospital. Salvador, Brazil

${ }^{2}$ Attendant doctor at the orthopedic department of Martagão Gesteira Children's Hospital. Salvador, Brazil

${ }^{3}$ Medicine student at the Faculdade de Tecnologia e Ciências - FTC. Salvador, Bahia, Brazil

${ }^{4}$ Medicine student at the Universidad de Ciencias Empresariales y Sociales- UCES. Buenos Aires, Argentina

\begin{abstract}
Introduction: hallux valgus is a complex deformity that covers the entire first radius of the foot, often accompanied by changes in the other pododactyl. In children and adolescents this condition is rare and underdiagnosed because these patients often do not seek treatment until the pain limits their daily activity and the selection of shoes. There is a great amount of researches that addresses and advocates several surgical techniques, such as soft tissue procedures and osteotomies, in particular the Chevron osteotomy which is the technique under study in this paper.
\end{abstract}

Objective: to evaluate the effectiveness of the Chevron technique associated with metatarsal tendon release in patients aged 1 to 20 years with hallux valgus, attended in the Martagão Gesteira Children's Hospital between January 2010 and December 2013.

Methods: cases series study, involving 11 children with hallux valgus who underwent Chevron osteotomy during the period January 2010 to December 2013.

Results: of the 11 children 03 were boys $(27.3 \%)$ and 08 were girls $(72.7 \%)$. The mean age was 11.63 years (SD = 1,689$)$, ranging from 10 to 15 years old. Three patients $(27.3 \%)$ had only the right foot affected, 03 patients $(27.3 \%)$ had only the left foot affected and 05 patients (45.5\%) had a deformity in both feet (bilateral). Postoperatively, 08 children (72.7 \%) showed the first ray angles within acceptable values. All children had cosmetic correction and 10 children (90.9 \%) had relief of pain and suitability for footwear.

Conclusion: this study showed that few children require surgical treatment for hallux valgus, but when it happens it is more common in female children and, when present, affects, in most cases, both feet. The study also showed that Chevron osteotomy is fully applicable to hallux valgus in children with mild to moderate cases.

\section{Introduction}

The hallux valgus is a complex deformity of the first radius which may be characterized by a lateral or valgus deviation of the hallux, a medial deviation of the first metatarsal, and an exostosis of the joint between the first metatarse and the hallux, often accompanied by other adaptive changes of the other pododactyli. Normal angulations between the first and second metatarses (IMA) range from $8^{\circ}$ to $9^{\circ}$, and the angle formed between the first metatarse and the hallux (HVA) is between $15^{\circ}$ and $20^{\circ}$ [1]. When these values are exceeded, we often find the first metatarse shortened and deviated in varus (medially) while the first pododactyl is deviated in valgus (laterally) and in a compensatory pronation. Factors such as the shortening of the first metatarse, the diminished or annulled crest between the sesamoids favors its lateral deviation to the first intermetatarsal space, leading to a decrease in the support of the first radius in the forefoot and consequently to a muscular imbalance and plantar alteration, corroborating with the worsening of the deformity $[2,3]$.

Some authors consider this deformity as having a congenital character [4]. In this age group, this pathology is not very frequent, mainly because it is not well diagnosed, since these patients often do not seek treatment until the pain limits their activities and the selection of footwear. In this way, we have the pain and inadequacy for footwear as the main indications for the surgical correction of the Hallux Valgus.
There is a great amount of researches that addresses and advocates several surgical techniques, such as soft tissue procedures (Duvriesmodified McBride technique), arthrodeses (Lapidus and McKeever technique) and osteotomies (Keller, Wilson, Akin, Michell), in particular the Chevron osteotomy which is the technique under study in this paper.

\section{Materials and methods}

This is a case series study that was carried out with children and adolescents aged between 1 to 20 years, attended at the orthopedic clinic of the Martagão Gesteira Children's Hospital (HMG). This hospital is the only exclusively pediatric hospital in the city of Salvador, Brazil.

All children and adolescents who undergone surgical treatment by Chevron osteotomy for fixation of the hallux valgus during the period of January 2010 and December 2013 in the HMG were studied.

Correspondence to: Fernando Cal Garcia Filho, Av. Euclides da Cunha, n610, Apt. 101, Graça. 40150-122, Salvador, Bahia, Brazil, Tel: +55 71 99971-2222; E-mail: garciafilho59@gmail.com

Key words: Hallux, Hallux Valgus, Chevron osteotomy

Received: June 03, 2017; Accepted: July 17, 2017; Published: July 20, 2017 
After consulting the hospital's record book of orthopedic surgery procedures for the period of January 2010 to December 2013, we verified the number of medical records of all patients submitted to Chevron osteotomy. After this procedure, we requested these patient's medical records from the coordination of the HMG to have their data analyzed. All variables of interest contained in the medical records were verified. The data was then studied, analyzed and the results were calculated in SPSS 20 .

The variables studied were: sex, age, laterality, classification of the deformity and the efficacy (correction of deformity) of the treatment.

Absolute and relative frequency calculations were performed for all variables. A non-parametric (chi-square of a sample) was used to verify the relation between the hallux valgus and the sex. The analysis was performed by the SPSS program 20.

\section{Results}

We studied 11 children who were evaluated during the preoperative period using clinical and radiological criteria. All had indication for surgical correction of the hallux valgus because they presented pain in the metatarsophalangeal joint and inadequacy for footwear. The sample consisted of 03 boys (27.3\%) and 08 girls (72.7\%) with p equal to 0.132 . The mean age was 11.63 years $(S D=1.689)$, median 11.00 years, maximum 15 years and minimum 10 years (Table 1 ).

Although there were 11 patients, in total, they were submitted to a total of 16 surgeries using Chevron technique, since 05 patients had bilateral deformity (45.5\%), 03 patients $(27.3 \%)$ had the deformity only in the right foot and 03 patients (27.3\%) only in the left foot (Table 2).

Regarding the severity of hallux valgus in the preoperative and postoperative period, Coughlin's classification was used to distinguish, through radiographic measurements of the HVA and IMA angles, the degree of deformity presented by the patient before and after the Chevron's surgery. In the preoperative period, 02 children (18.2\%) presented mild deformity, 08 children $(72.7 \%)$ presented moderate deformity and one child (9.1\%) presented severe deformity. In the postoperative period, 08 children $(72.7 \%)$ presented normal angulations (no deformity), 02 children (18.2\%) had a mild deformity and one child (9.1\%) had a moderate deformity (Table 3 ).

All patients had a cosmetic correction, 10 patients (90.9\%) had pain relief and shoe suitability, and one child (9.1\%) persisted with pain when standing for a long time and inadequate for shoes.

Table 1. Demographic data of the children submitted to Chevron's technique in Martagão Gesteira Children's Hospital, from 2010 to 2013.

\begin{tabular}{|c|c|c|c|}
\hline Variable & $\mathbf{n}$ & $\mathbf{\%}$ & $\mathbf{p}$ \\
\hline Gender & & & \\
\hline Male & 3 & 27,3 & 0,132 \\
\hline Female & 8 & 72,7 & \\
\hline Total & 11 & 100,0 & \\
\hline Age & & & \\
\hline \multicolumn{1}{|c|}{10 years } & 3 & 27,3 & \\
\hline 11 years & 4 & 36,4 & \\
\hline 12 years & 1 & 9,1 & \\
\hline 13 years & 1 & 9,1 & \\
\hline 14 years & 1 & 9,1 & \\
\hline 15 years & 1 & 9,1 & \\
\hline Total & 11 & 100,0 & \\
\hline $\begin{array}{l}\text { Mean } \pm \text { SD } 11,63 \pm 1,689 \\
\text { Median } 11,00 \\
\text { Mode } 11,00\end{array}$ & & & \\
$\begin{array}{l}\text { Maximum } 15 \\
\text { Minimum } 10\end{array}$ & & & \\
\hline
\end{tabular}

Table 2. Laterality of the feet affected by the hallux valgus in the HMG during the period of 2010 to 2013.

\begin{tabular}{|c|c|c|}
\hline Laterality & $\mathbf{N}$ & $\mathbf{\%}$ \\
\hline Right & 3 & 27,3 \\
\hline Left & 3 & 27,3 \\
\hline Bilateral & 5 & 45,5 \\
\hline Total & 11 & 100,0 \\
\hline
\end{tabular}

Table 3. Severity classification of hallux valgus in the pre and postoperative period.

\begin{tabular}{|c|c|c|}
\hline Surgery Period & N & \% \\
\hline Preoperative & & 18,2 \\
\hline Mild Deformity & 2 & 72,7 \\
\hline Moderate Deformity & 8 & 9,1 \\
\hline Severe Deformity & 1 & 100,0 \\
\hline Total & 11 & \\
\hline Postoperative & & 72,7 \\
\hline No Deformity & 8 & 18,2 \\
\hline Mild Deformity & 2 & 9,1 \\
\hline Moderate Deformity & & 0,0 \\
\hline Severe Deformity & 0 & 100,0 \\
\hline Total & 11 & \\
\hline
\end{tabular}

\section{Discussion}

The hallux valgus remains a very controversial pathology with etiological bases little known. Mens and Lord [5], in 2005, and Castro et al. [6], in 2009, reported that hallux valgus is a condition that increases according to age [7] and, as shown in this study, children less than 10 years old with hallux valgus were not found in the main hospital for children care in the state of Bahia, Brazil (HMG). This is probably due to the lack of diagnosis of the deformity and to the fact that it is a pathology that, although present, only leads the patient to a consultation when pain or inadequacy for shoes usage are present.

Most cases of hallux valgus in adolescents requiring surgery present an increased angle between the first and second metatarses [1]. This means that soft tissue surgery alone has a high recurrence rate due to medial deviation of the first metatarse. Correction of the adolescent's hallux valgus requires not only the realignment of the metatarsophalangeal joint but also correction of the varus deformity of the first metatarse.

Osteotomy by the Wilson technique promotes good correction of this deformity, leaving a wide contact surface between fragments; However, a disadvantage is to promote a significant shortening of the first metatarse [8]. Thus, it is contraindicated in patients who already present the first metatarse shortened, because of the load transfer to the lateral metatarsal heads due to the increased shortening. In addition, this osteotomy is quite unstable and allows the fragments to deviate.

Mitchell's osteotomy also provides a good correction of the first metatarse varism; However, it promotes a slight shortening of the same metatarse in addition to being made in cortical bone (diaphysis), prolonging the consolidation time. Also a dorsal deviation of the distal fragment may occur, which compromises the result of this surgery [9-12].

The main advantages of Chevron osteotomy in relation to other techniques are mainly related to the rate of complications. Because it is performed on spongy bone, it requires less time for consolidation. It does not produce shortening in the first metatarse, does not allow dorsal deviation of the metatarsal head, and its technical execution is easier than that of Mitchell's osteotomy. The main limitation of the Chevron technique is that it is only indicated for mild deformities 
(around $15^{\circ}$ ), because the distal fragment can only move laterally up to one-third the width of the proximal fragment. Another concern is that there may be a slight increase in the avascular necrosis rate of the metatarsal head; However, Corlles $[1,13]$ in a series of 148 cases submitted to such procedures recorded only one case of necrosis.

Because of the small number of cases in this series, a fact justified by the low frequency of this pathology and the few cases requiring surgical treatment, this study could never attempt to establish conducts in the treatment of hallux valgus in children and adolescents. However, the present author joins those who argue that Chevron osteotomy is an easy-to-perform surgical procedure whose postoperative period is facilitated by the stability of the fragments.

\section{Conclusion}

The present study demonstrated that few children require surgical treatment for hallux valgus, but when this happens it is more common in female children and it most commonly affects both feet.

The study also demonstrated that Chevron osteotomy is fully applicable to hallux valgus in the child in cases of mild to moderate deformity (intermetatarsal angle around $15^{\circ}$ ), remaining as an excellent treatment option.

\section{Authorship and contribution}

Fernando Cal Garcia Filho: substantial contributions to conception and design of the present study. Revised the study critically for important intellectual content. Made a final approval of the version to be published and agreed to act as guarantor of the work.

Lucas Cortizo Garcia: substantial contributions to acquisition of data and drafting the article. Made a final approval of the version to be published and agreed to act as guarantor of the work.

Fabio Silveira Matos: substantial contributions to conception and design of the present study. Revised the study critically for important intellectual content. Made a final approval of the version to be published and agreed to act as guarantor of the work.

Lucas Rocha de Jesus: substantial contributions to analysis and interpretation of data. Contributed to the drafting of the article. Made a final approval of the version to be published and agreed to act as guarantor of the work.

Magda Leão Pinheiro: substantial contributions to analysis and interpretation of data. Contributed to the drafting of the article. Made a final approval of the version to be published and agreed to act as guarantor of the work.

Fernanda Cortizo Garcia: substantial contributions to analysis and interpretation of data. Contributed to the drafting of the article. Made a final approval of the version to be published and agreed to act as guarantor of the work.

Matheus Vasconcelos Goes Mendes: substantial contributions to analysis and interpretation of data. Contributed to the drafting of the article. Made a final approval of the version to be published and agreed to act as guarantor of the work.

\section{Funding information and competing interests}

The present study has not been funded by any instutition and all its costs were covered by the authors.

The Authors disclose that the present study has no financial or non-financial conflicts of interests.

\section{References}

1. Corless JR (1976) A modification of the Mitchell procedure. J Bone Joint Surg [Br] 58: 138 .

2. Richardson EG, Crenshaw AH (1989) Cirurgia ortopédica de Campbell. Rio de Janeiro 35: 865-867.

3. Viladot A (1986) Dez lições de patologias do pé. São Paulo 8: 153-160.

4. Zimmer TJ, Johnson KA, Klassen RA (1989) Treatment of hallux valgus in adolescents by the chevron osteotomy. Foot Ankle 9: 190-193. [Crossref]

5. Mann R, Coughlin M (1999) Adult hallux valgus. Surgery of the foot and ankle 7th [edn] 151-267.

6. Nery C (2001) Hálux valgo. Rev Bras Ortop 36: 183-99.

7. Campanacho V (2012) Hallux valgus: uma condição patológica esquecida na Antropologia. Cadernos do GEEvH 1:21-31.

8. Wilson JN (1963) Oblique displacement osteotomy for hallux valgus. $J$ Bone Joint Surg $\mathrm{Br}$ 45: 552-556. [Crossref]

9. Dias, De S (1984) Distal metatarsal osteotomy for adolescente hallux valgus. J Pediatr Orthop 4: 32-38.

10. Hawkins FB, Mitchell CL, Hendrick DW (1945) Correction of hallux valgus by metatarsal osteotomy. J Bone Joint Surg 27: 387.

11. Koop, Steven E (1992) The child's foot and Ankle, New York, J.C. Drennann 21: 417-423.

12. Luba, R, Rosman M (1984) Bunions in children-treatment with a modified Mitchell osteotomy. J Pediatr Orthop 4: 44-47. [Crossref]

13. Johnson KA, Cofield RH, Morrey BF (1979) Chevron osteotomy for hallux valgus. Clin Orthop Relat Res: 44-47. [Crossref]

Copyright: (C2017 Filho FCG. This is an open-access article distributed under the terms of the Creative Commons Attribution License, which permits unrestricted use, distribution, and reproduction in any medium, provided the original author and source are credited. 